\title{
Detection of Pathological Changes in the Aorta during Thoracic Aortic Aneurysm Progression on Molecular Level
}

\author{
Miroslava Rabajdová, ${ }^{1}$ Peter Urban, ${ }^{1}$ Ivana Špaková, ${ }^{1}$ Artemiou Panagiotis, ${ }^{2}$ \\ Michaela Ferenčáková, ${ }^{1}$ Dušan Rybár, ${ }^{3}$ Nikita Bobrov, ${ }^{4}$ František Sabol, ${ }^{2}$ and \\ Mária Mareková ${ }^{1}$ \\ ${ }^{1}$ Department of Medical and Clinical Biochemistry, Faculty of Medicine, Pavol Jozef Šafárik University, Košice, Slovakia \\ ${ }^{2}$ Department of Heart Surgery, Faculty of Medicine, Pavol Jozef Šafárik University and VUSCH, Košice, Slovakia \\ ${ }^{3}$ Department of Anaesthesiology and Resuscitation, Faculty of Medicine and VUSCH, Košice, Slovakia \\ ${ }^{4}$ Department of Forensic Medicine, Pavol Jozef Šafárik University, Košice, Slovakia
}

Correspondence should be addressed to Mária Mareková; maria.marekova@upjs.sk

Received 24 May 2017; Revised 12 July 2017; Accepted 24 August 2017; Published 12 October 2017

Academic Editor: Zhongjie Shi

Copyright (C) 2017 Miroslava Rabajdová et al. This is an open access article distributed under the Creative Commons Attribution License, which permits unrestricted use, distribution, and reproduction in any medium, provided the original work is properly cited.

\begin{abstract}
The progression of thoracic aortic aneurysm depends on regulation of aortic wall homeostasis and on changes in the structural components of the extracellular matrix, which are affected by multiple molecular signalling pathways. We decided to correlate the diameter of ascending thoracic aneurysm with gene expression of inflammation markers (IL-6, CRP), cytokine receptors (IL-6R, TNFR1, and TNFR2), and extracellular matrix components (Emilin-1, MMP9, and TIMP) for detection of the degree of pathological process of TAA formation. The experimental group was divided into three groups according to the diameter of the aortic aneurysm. Whole blood and tissue samples were properly collected and used for nucleic acid, chromatin, and protein isolation. The mRNA levels were detected by qRT-PCR. For the detection of protein levels a Cytokine Array IV assay kit was used in combination with a biochip analyzer. In aortic tissue, significant positive correlations were found between increased mRNA levels of inflammatory cytokines (CRP and IL-6) on both mRNA levels in tissue and protein from the blood with maximum in stage 3. Changes of gene expression of selected genes can be used for the experimental study of the inflammatory receptor inhibitors during trials targeted on slowing down the progress of aortic wall aneurysm.
\end{abstract}

\section{Introduction}

Thoracic aorta diseases are among the most common causes of death in the US and other developed countries. The incidence of thoracic aortic aneurysm has been estimated at 6 cases per 100,000 persons per year [1], and its prevalence has been estimated at $3-4 \%$ in patients over age 65 years old. According to possible endovascular therapy (EVT) or its combination with surgical therapy, it seems most practical to divide thoracic aorta diseases into acute aortic syndromes (AAS) and chronic aneurysmal transformation (thoracic aortic aneurysm-TAA) [2]. The AAS group includes penetrating aortic ulcer (PAU), bordered aortic intramural hematoma (IMH), and classical acute aortic dissection, while chronic aneurysmal transformation includes right degenerative aneurysm of the ascending or descending aorta, false TAA (pseudoaneurysm), and posttraumatic TAA [3].

The growth rate of TAA varies by lesion location, with ascending aneurysms growing at a rate of $0.07 \mathrm{~cm}$ per year. The rate of growth has also been demonstrated to increase with aneurysm size [4]. When the diameter of the thoracic aorta is more than $3.5 \mathrm{~cm}$, or twice the normal diameter, the thoracic aorta is considered aneurysmal. The risk of aneurysm rupture is proportionate to its size [5]. The decision of whether to surgically treat a patient is based on aneurysm size and patient operative risk. Annual risk of rupture, dissection, or death is $14.1 \%$ in patients with 
TABLE 1: Demographic and clinical characteristics of subjects.

\begin{tabular}{|c|c|c|c|c|}
\hline & Control & Stage 1 & Stage 2 & Stage 3 \\
\hline Number of patients & 35 & 12 & 34 & 14 \\
\hline Gender (female \%) & $20 / 35(57 \%)$ & $2 / 12(17 \%)$ & $5 / 34(14.7 \%)$ & $2 / 14(14.3 \%)$ \\
\hline Age (years) & $45 \pm 9.6$ & $49.9 \pm 16.6$ & $55.1 \pm 14.7$ & $54.5 \pm 14.1$ \\
\hline Aorta diameter (mm) & - & $43 \pm 2.3$ & $51 \pm 2.8$ & $59.5 \pm 3.7$ \\
\hline AR/AS & - & $6 / 6(50 / 50 \%)$ & $19 / 15(56 / 44 \%)$ & $8 / 6(57 / 4 \%)$ \\
\hline $\mathrm{BAV} / \mathrm{TAV}$ & - & $8 / 4(67 \%)$ & $21 / 13(62 \%)$ & $8 / 6(57 \%)$ \\
\hline Hypertension & $5 / 35(14 \%)$ & $8 / 12(67 \%)$ & $18 / 34(52.9 \%)$ & $12 / 14(85.7 \%)$ \\
\hline Diabetes mellitus & 0 & $1 / 12(8 \%)$ & $3 / 34(8.8 \%)$ & $2 / 14(14.3 \%)$ \\
\hline Current smokers & $9 / 35(26 \%)$ & $7 / 12(58.3 \%)$ & $22 / 34(64.7 \%)$ & $11 / 14(78.6 \%)$ \\
\hline BMI & $26.4 \pm 4.2$ & $29.4 \pm 6.4$ & $29.6 \pm 4.9$ & $26.99 \pm 4.9$ \\
\hline Weight (kg) & $76.9 \pm 15.2$ & $89.2 \pm 16.9$ & $89.3 \pm 13.7$ & $87.4 \pm 16.3$ \\
\hline
\end{tabular}

aneurysms larger than $6 \mathrm{~cm}$, compared with $6.5 \%$ for aneurysms between 5 and $6 \mathrm{~cm}$ [6]. Additionally, repair is suggested in patients with documented aneurysm growth of $>1 \mathrm{~cm}$ per year [7]. The progression of aortic aneurysm probably results from a combination of chronic inflammation, hemodynamic stress, aortic mechanical injury, and epidemiologic risk factors. Aortic functions as well as regulation of aortic wall homeostasis depend on changes in the structural components of the extracellular matrix (ECM), which are affected by multiple molecular signalling pathways.

Microfibrils, as the main structural component of aortic wall ECM, provide a scaffold for the lysyl oxidase protein family to cross-link tropoelastin monomers to form mature elastic fibres [8]. Microfibrils are composed mainly from fibrillin and several microfibril-associated proteins (elastin microfibril interface-located protein 1 (Emilin-1), microfibril-associated glycoproteins (MAGP-1,2), and fibulins) [9]. Emilin-1 is known to be a binding precursor of TGF- $\beta$, called pro-TGF$\beta$, and inhibits its maturation by furin convertases [10]. Defects in Emilin-1 expression affect the formation and function of elastic lamellae, increasing the degree of inflammation.

Inflammation participates in the pathogenesis of aortic aneurysm formation by the migration of T-lymphocytes and macrophages diffusely throughout the adventitia to the tunica media [11]. Several cytokines and chemokines that are produced during their transfer (TNF- $\alpha$, interferon- $\gamma$, IL-1, IL-2, IL-6, and IL-8) are upregulated and promote the recruitment of other inflammatory cells to the aortic wall [12]. The main protein of the acute phase of inflammation-serum Creactive protein (CRP) - has been reported in patients with stenotic atherosclerotic disease and is associated with an increased risk of developing cardiovascular events [13]. However, only a few articles have been published describing serum CRP and IL-6 in patients with TAA. Inflammatory changes consequently induce the secretion of matrix metalloproteinases (MMP), elastase, and collagenase from macrophages and neutrophils that are capable of directly degrading the ECM and may also contribute to the detachment of smooth muscle cells from the ECM, leading to cell death [14]. The important regulators of local MMP activity are tissue inhibitors of metalloproteinases (TIMPs) [15]. Animal data support a role for MMP and TIMP in the development of aortic aneurysm, especially in Marfan syndrome [16]. Most of the data on MMPs and aortic aneurysm are from studies of abdominal aortic aneurysms, while data is lacking on MMP in TAA. Studies of TAA have focused on changes in genetic expression, which does not necessarily translate into the changes in protein expression that determine the effect on the aorta [17]. The proteolytic theory of TAA development envisions increased concentrations of MMP and reduced concentrations of TIMP in the aorta acting in concert to increase ECM degradation, leading to an aorta that is more likely to expand in response to the hemodynamic load [18]. In this study, we decided to correlate the diameter of ascending thoracic aneurysm with gene expression of inflammation markers (IL-6, CRP), cytokine receptors (IL-6R, TNFR1, and TNFR2), and components of ECM (Emilin-1, MMP9, and TIMP) for detection of the degree of pathological process of TAA formation. The obtained results could help surgeons decide if the progression of aortic aneurysm is too fast and give them a chance to improve the lifetime and healthcare of patients suffering with progressive TAA.

\section{Materials and Methods}

2.1. Experimental Groups and Sample Collection. The experimental group $(n=60)$ consisted of patients suffering from thoracic aortic aneurysm, regurgitation, and aortic valve stenosis, who were divided into three groups according to the diameter of the aortic aneurysm (stage 1: $43 \pm 2.3 \mathrm{~mm}$, stage $2: 51 \pm 2.8 \mathrm{~mm}$, and stage $3: 59.5 \pm 3.7 \mathrm{~mm}$ ). Each group was characterized by age, gender, BMI, presence of aortic regurgitation or aortic stenosis (AR/AS), bicuspid or tricuspid aortic valve (BAV/TAV), hypertension, diabetes mellitus, current smoking, and family predispositions for cardiovascular diseases (Table 1). Results of preoperative medical tests of individual biochemical and haematology biomarkers were within acceptable physiology intervals according to the patient's clinical status.

Whole blood was collected from all patients of the experimental group during the standard preoperative examination done in cooperation with the Eastern Slovak Institute of 
Cardiovascular Diseases (VUSCH). Results of preoperative medical tests of individual biochemical and hematology biomarkers were within acceptable physiology intervals according to the patient's clinical status. The tissue samples of patients in the experimental group were collected during the following surgical procedures: replacement of the ascending aorta, valve-sparing procedure (aortic root remodeling), and replacement of the aortic valve (AVR) with a mechanical or biological prosthetic valve. Other concomitant procedures were replacement of the mitral valve (MVR) and off-pump coronary artery revascularization (OPCAB). The operations were performed through a median sternotomy with the use of cardiopulmonary bypass, mild hypothermia, and cardioplegic arrest. Cardio anesthesia was performed according to the standard protocol.

2.2. Control Group and Sample Collection. Control group $(n=35)$ blood samples were taken from blood donors in cooperation with the UNLP Department of Haematology and Transfusiology. The control group was composed of people with negative results from biochemical and haematological screening medical tests. Donors declared themselves free of any symptoms of cardiovascular diseases, and their clinical imaging methods, ultrasonography and computed tomography angiography, were also negative. Control materials of the ascending part of thoracic aortic tissues $(n=10)$ were obtained from the Department of Forensic Medicine of LF UPJŠ and UNLP. These necroptic samples were collected immediately after death. Cause of deaths was not related to pathology, such as thoracic aortic aneurysm, regurgitation or stenosis of the aortic valve, or any pathology associated with myocardial damage. Histopathology detection of the myocardial tissue samples did not show any noticeable changes.

All clinical investigations using human samples have been carried out in accordance with the code of ethics of the world medical association (Declaration of Helsinki). Healthy subjects in the control group and patients in the experimental group answered a medical sheet and questionnaire. Patients were informed by their doctor about the use of their blood and tissue for experimental diagnostic purposes. Informed consents were signed. Ethical consent for this study was given by the institutional committee on human research, was approved by the ethical committee of the Eastern Slovak Institute of Cardiovascular diseases (VUSCH), and was compliant with ethical standards on human experimentation and with the Declaration of Helsinki.

2.3. RNA, DNA, and Chromatin Isolation. All tissue samples were frozen immediately after harvesting at $-196^{\circ} \mathrm{C}$ and stored in a freezer at $-80^{\circ} \mathrm{C}$. Whole blood samples, collected into Paxgene test tubes, were stored in a fridge for 2 hours and then used for isolation of DNA and RNA. For isolation of total RNA from $40 \mathrm{mg}$ of tissue or $2 \mathrm{ml}$ of whole blood, the isolation protocol RNeasy Mini Kit (Qiagene, Hilden, Germany) was used following the manufacturer's protocols. Chromatin isolation starts from $40 \mathrm{mg}$ of tissue from the ascending part of the thoracic aorta. The tissue was washed using ice cold $1 \times$ PBS. After centrifugation at $1300 \mathrm{rpm} /$
$5 \mathrm{~min} / 4^{\circ} \mathrm{C}$, the supernatant was carefully removed and the pellet was resuspended thoroughly in $2 \mathrm{ml}$ of $1 \times \mathrm{PBS}$ containing of $1 \%$ formaldehyde for cross-linking the cells/for $8 \mathrm{~min} /$ $37^{\circ} \mathrm{C}$. Cross-linking was stopped by the addition of $125 \mathrm{mM}$ of glycine. After centrifugation at $1300 \mathrm{rpm} / 5 \mathrm{~min} / 4^{\circ} \mathrm{C}$, the pellet was washed $5 \times$ with ice cold $1 \times$ PBS. The pellet was lysated with lysis buffer (LB consists of $155 \mathrm{mM} \mathrm{NH} 4 \mathrm{Cl}$, $10 \mathrm{mM} \mathrm{KHCO} 3$, and $0.1 \mathrm{mM}$ EDTA pH 7.4) on ice for 10 minutes with gentle mixing. After centrifugation at $1500 \mathrm{rpm} / 5 \mathrm{~min} / 4^{\circ} \mathrm{C}$, the cell lysates were sonicated with a Bioruptor (Diagenode, Denville, USA) at high intensity for $5 \mathrm{~min}$, with $30 \mathrm{~s}$ on/off intervals. For preclearing of chromatin, Protein G agarose beads (Merck Millipore, Prague, Czech Republic) were used for 1 hour $/ 4^{\circ} \mathrm{C}$. Chromatin fragments with lengths of $200 \mathrm{bp}$ were visualized on agarose gel. Isolated cells were snap-frozen and stored at $-80^{\circ} \mathrm{C}$. A Nanodrop LC 3000 (Thermo Scientific, Bratislava, Slovak Republic) was used for measuring the concentration and purity of isolated chromatin, DNA, and RNA.

2.4. $q R T-P C R$. For detection of changes in the mRNA expression levels of specific genes IL-6, hsCRP, TIMP, Emilin-1, and $M M P 9$, a Rotor-Gene Q-PCR thermocycler (Qiagene, Hilden, Germany) was used. RNA isolated from blood was transcribed into cDNA by using specific reverse primers individually for each gene and an M-MLV reverse transcriptase kit (Sigma-Aldrich). We also isolated chromatin from tissue and detected transcription activity of RNA Pol II, Emilin-1, and MMP9 using qRT-PCR methods after chromatin immunoprecipitation. In all, triplicated analyses were performed for each gene. Selected experimental genes (IL-6, hsCRP, TIMP, Emilin-1, and MMP9) and control housekeeping genes (HPRT, ETNK, and GAPDH) were amplificated by using 34 cycles $\left(95^{\circ} \mathrm{C} / 5 \mathrm{~min}, 95^{\circ} \mathrm{C} / 15 \mathrm{~s}, 58-62^{\circ} \mathrm{C} / 20 \mathrm{~s}\right.$, and $72^{\circ} \mathrm{C} / 25 \mathrm{~s}$ ) using appropriate specific primer sequences (Table 2). More detailed primer sequences are in Supplementary Table 5 available online at https://doi.org/10.1155/2017/ 9185934. Numerical quantification of changes in the expression of mRNA levels was evaluated by the comparative quantification and $\mathrm{Ct}$ value $\mathrm{Q}$ Rotor gene Software. The determination starts when, for each sample, difference between $\Delta \mathrm{Ct}$ of studied gene and control gene was calculated, then subtracted between $\Delta \mathrm{Ct}$ of sample with unknown concentration and $\Delta \mathrm{Ct}$ of the calibrator. The final result was a multiple of the calibrator concentration.

2.5. Copy Number Variation Analysis. Analysis of gene copies was performed after the isolation of DNA, using specific primers for all exon-specific gene domains of $I L-6$, hs $C R P$, TIMP, Emilin-1, and MMP9 in comparison with HPRT and GAPDH. Amplification of specific genes was run for 33 cycles $\left(95^{\circ} \mathrm{C} 5 \mathrm{~min}, 95^{\circ} \mathrm{C}\right.$ for 15 seconds, $58^{\circ} \mathrm{C}-60^{\circ} \mathrm{C}$ for 20 seconds, and $72^{\circ} \mathrm{C}$ for 25 seconds) using the appropriate primer sequences with the Rotor-Gene Q-PCR (Qiagene, Hilden, Germany) thermocycler.

2.6. ChIP qRT-PCR. Precleared chromatin (125 ng) was incubated with selected antibodies (anti-RNAPII CTD YSPTSPS, anti-Emilin-1, and anti-MMP9, ab817, ab185953, ab 38898 
TABLE 2: Localization of the chromosome of specific genes (http://www.genome.ucsc.edu).

\begin{tabular}{lccc}
\hline Name of gene & Chromosomal localization & Size of gene in bp including UTR side & Analysis place of gene Ex-exon \\
\hline IL-6 & $7 \mathrm{p} 15.3$ & $22,766,766-22,770,157$ & Prom, Ex1, Ex4 \\
CRP & $1 \mathrm{q} 23.2$ & $159,682,079-159,684,379$ & Ex1, Ex2 \\
TIMP & Xp11.23 & $47,441,712-47,446,188$ & Ex1, Ex3 \\
Emilin-1 & $2 \mathrm{p} 23.3$ & $27,301,435-27,309,265$ & Prom, Ex1, Ex3, Ex4, Ex6 \\
MMP9 & $20 \mathrm{q} 13.12$ & $44,635,634-44,647,114$ & Prom, Ex1, Ex5, Ex9, Ex13 \\
GAPDH & $12 \mathrm{p} 13.1$ & $6,643,585-6,647,537$ & Ex2, Ex3, EX4 \\
HPRT & Xq26.2-q26.3 & $133,594,175-133,634,698$ & Ex3, Ex6 \\
ETNK & $12 p 12.1$ & $22,778,076-22,843,608$ & Ex1, Ex3, Ex7 \\
\hline
\end{tabular}

(Abcam, Cambridge, UK) at $4^{\circ} \mathrm{C}$ overnight. The RNase treatment was done 30 minutes before incubation using a mix of RNase A/T (Roche Slovakia, Bratislava, Slovak Republic). Protein IgG agarose beads (Merck Millipore, Prague, Czech Republic) were used for bonding with immunocomplexes and cross-linking them. The next procedure used the downward line of cleaning buffer solutions in the order buffers I and II (500 mM NaCl, $50 \mathrm{mM}$ HEPES (pH 7.5), 1\% Triton$\mathrm{X}-100,0.1 \%$ sodium deoxycholate, and $1 \mathrm{mM}$ EDTA (pH 7.5)), buffer III (10 mM Tris-Cl, $250 \mathrm{mM} \mathrm{LiCl,} 0.5 \%$ NP-40 (pH 8.0), 0.5\% sodium deoxycholate, and $1 \mathrm{mM}$ EDTA (pH 7.5)), and buffer IV (1 mM EDTA, 10 mM Tris$\mathrm{HCl}$ ). Immunoprecipitated DNA was eluted from the beads in TE Tris-EDTA buffer with $1 \%$ SDS. For reverse crosslinking of the samples, a solution was used containing $5 \mathrm{~mol} / \mathrm{l} \mathrm{NaCl}, 5 \mathrm{~g} / \mathrm{ml}$ of enzyme RNaseA (Roche Slovakia, Bratislava, Slovak Republic), 1 M Tris-HCL (Sigma-Aldrich, Bratislava, Slovak Republic), and $20 \mathrm{~g}$ of proteinase K (Roche Slovakia, Bratislava, Slovak Republic), which was incubated at $65^{\circ} \mathrm{C}$ overnight and purified using a Qiagen PCR purification columns kit (28104, Qiagene, Hilden, Germany). DNA was eluted twice with $30 \mu \mathrm{l}$ of RNAase/DNAase free water (Qiagene, Hilden, Germany). An aliquot of $2 \mu \mathrm{l}$ of each sample was used for qRT-PCR using SensiMix (Bioline, Luckenwalde, Germany). Amplification was performed on a Qiagene Rotor-Gene Q-PCR thermocycler using the protocol: 30 cycles $\left(95^{\circ} \mathrm{C}\right.$ for $5 \mathrm{~min}, 95^{\circ} \mathrm{C}$ for $15 \mathrm{~s}, 60^{\circ} \mathrm{C}$ for $20 \mathrm{~s}$, and $72^{\circ} \mathrm{C}$ for $25 \mathrm{~s}$ ). All primer pairs (SigmaAldrich, Bratislava, Slovak Republic) used for ChIP analysis were designed using the Internet databases (http://www. genome.ucsc.edu/ and http://www.bioinformatics.org/sms/ rev_comp.html). The primer pairs are listed in Table 2.

2.7. Protein Analysis by Randox Biochip. For the detection of protein levels in the serum of both the experimental and control groups, a Cytokine Array IV assay kit was used in combination with a biochip analyzer (Evidence Investigator, Randox Laboratories Ltd., London, UK). Detection of proteins IL-6, IL-6R, hsCRP, MMP9, TNFR1, and TNFR2 started with the incubation of a sample with $200 \mu \mathrm{l}$ of assay buffer for 1 hour $/ 37^{\circ} \mathrm{C} / 370 \mathrm{rpm}$ of $100 \mu \mathrm{l}$. After incubation, the procedure continued by decantation of the liquid and the washing of each well 2 times. The second incubation using the same conditions continued after adding conjugation buffer. After the second incubation, another decantation of liquid and the washing of each well 4 times were done. A mixture of luminol-EV-70l together with hydrogen peroxide was added to each well and incubated for 2 minutes. Visualization and calculation of the proteins levels $(\mathrm{ng} / \mathrm{ml})$ of each biomarker were performed using the Evidence Investigation biochip software version 4.

2.8. Statistical Analysis. All values are expressed as means $\pm \mathrm{SD}$ for normally distributed data. Differences in proportions of categorical variables were analysed using Pearson chi-squared test, and continuous variables with normally distributed values were analysed using the Student $t$-test, whereas nonnormally distributed continuous data were analysed with Mann-Whitney $U$-test for two independent samples and Kruskal-Wallis test for more than two independent samples. Possible associations between aneurysm diameter and selected markers were evaluated by Pearson correlation test. Relationship between progression of aneurysm and selected markers was evaluated by linear regression. The level of statistical significance was set at $p<0.05$. All analyses were performed using IBM SPSS 22.00 statistical software package.

\section{Results}

During the analysis of demographic data impact on the formation and progression of the aortic aneurysm, there were no any significant correlations found. We found that there is no difference in mean age between groups divided by aortic diameter. Differences are not statistically significant ( $r s=0.293, p=0.084$ ). Due to the low number of women, there is no statistically significant difference in the male/ female ratio in the individual aortic diameter categories ( $r s=0.240, p=0.070$ ). Other demographic data (obesity, smoking, hypertension, and diabetes) also showed no significant correlation with aortic diameter with $p>0.05$.

\subsection{Changes in the Levels of Cytokines and Their Receptors.} The real-time PCR for IL-6 mRNA (Figure 1) in aortic tissue showed increased expression rising from stage 1 to the maximum in stage $3(650 \%$ higher, $p<0.001)$ versus aortic controls.

Immunochemical evaluation (Figure 2) of the blood serum showed a similar increase in the levels of final protein IL-6. 


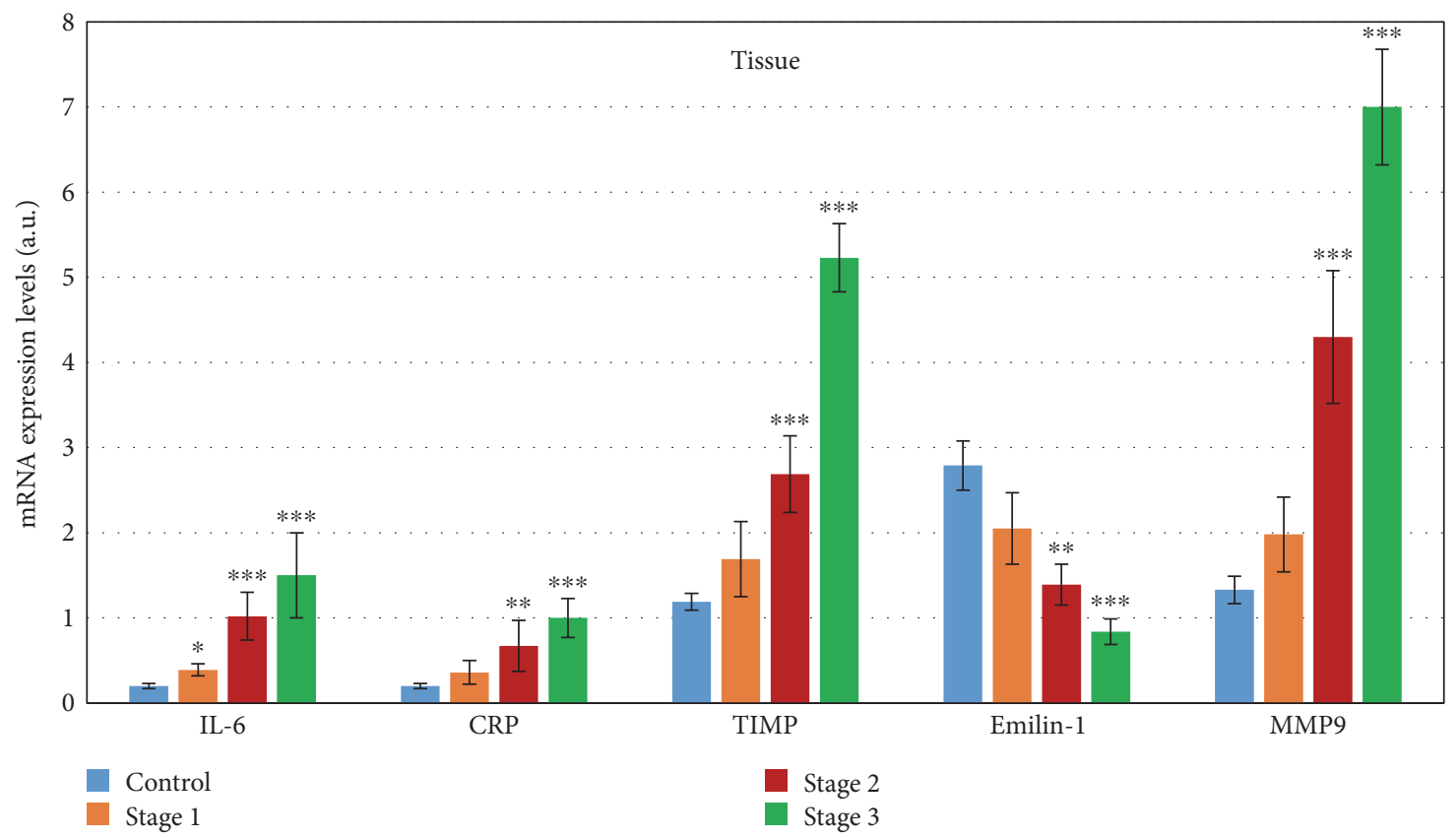

FIGURE 1: Expression of marker genes on mRNA levels in tissue of the patients with different stages of TAA. The mRNA levels of all detected genes were compared to controls $(\mathrm{C}, n=10)$. All data are presented as average \pm SD: 1 -mean aortic diameter $43 \pm 2.3 \mathrm{~mm}(n=10), 2-$ mean aortic diameter $51 \pm 2.8 \mathrm{~mm}(n=34)$, and 3 -mean aortic diameter $59.5 \pm 3.7(n=14) .{ }^{*} p<0.05,{ }^{* *} p<0.01$, and ${ }^{* * *} p<0.001$ mean statistical significance. Maximal levels reached values about $400 \%$ higher than controls $(p<0.001)$.

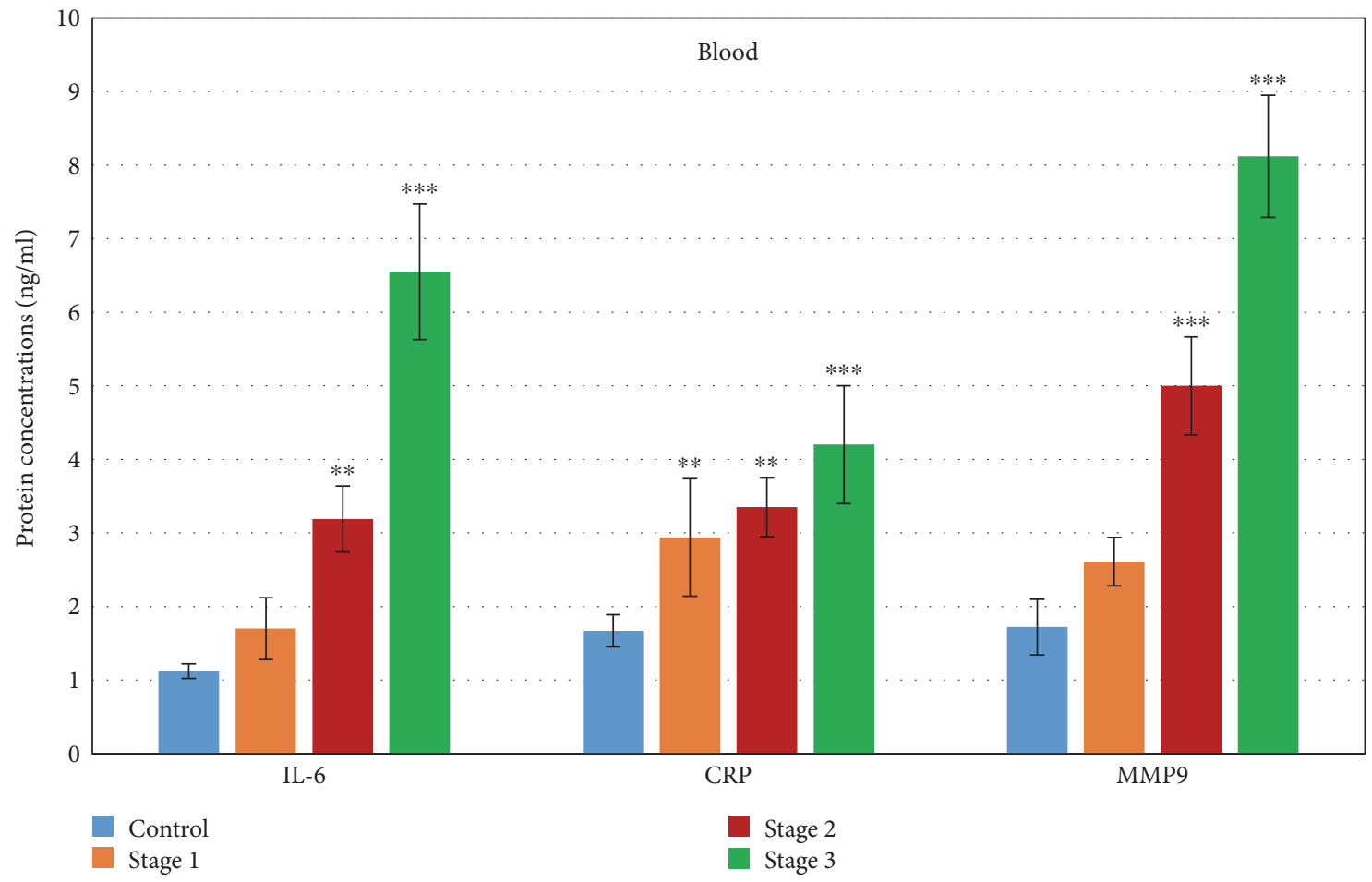

FIGURE 2: Expression of marker genes on protein levels in the blood of patients with different stages of TAA. The protein levels of all detected genes were compared to controls $(\mathrm{C}, n=10)$. All data are presented as average \pm SD: $1-$ mean aortic diameter $43 \pm 2.3 \mathrm{~mm}(n=10), 2-$ mean aortic diameter $51 \pm 2.8 \mathrm{~mm}(n=34), 3$-mean aortic diameter $59.5 \pm 3.7(n=14)$., ${ }^{* *} p<0.01$ and ${ }^{* * *} p<0.001$ mean statistical significance. 
TABLE 3: Spearman correlations and linear regression between the mRNA, protein levels, and aortic diameter for selected cytokines and their receptors.

\begin{tabular}{|c|c|c|c|c|c|c|c|}
\hline & \multicolumn{2}{|c|}{ mRNA in aortic tissue } & \multicolumn{5}{|c|}{ Protein levels in blood } \\
\hline & CRP & IL-6 & CRP & IL-6 & IL-6R & TNFR1 & TNFR2 \\
\hline Correlation coefficient & $0.489^{* *}$ & $0.554^{* *}$ & 0.025 & 0.320 & $-0.37^{*}$ & 0.272 & 0.268 \\
\hline$p$ value & 0.015 & 0.017 & 0.642 & 0.524 & 0.024 & 0.058 & 0.063 \\
\hline Unstandardized coefficient & 0.105 & $0.710^{* * *}$ & 0.027 & -0.006 & 0.007 & 0.966 & 0.771 \\
\hline$p$ value & 0.197 & 0.000 & 0.051 & 0.503 & 0.004 & 0.177 & 0.120 \\
\hline
\end{tabular}

Statistical significance: ${ }^{*} p<0.05,{ }^{* *} p<0.01$, and ${ }^{* * *} p<0.001$.

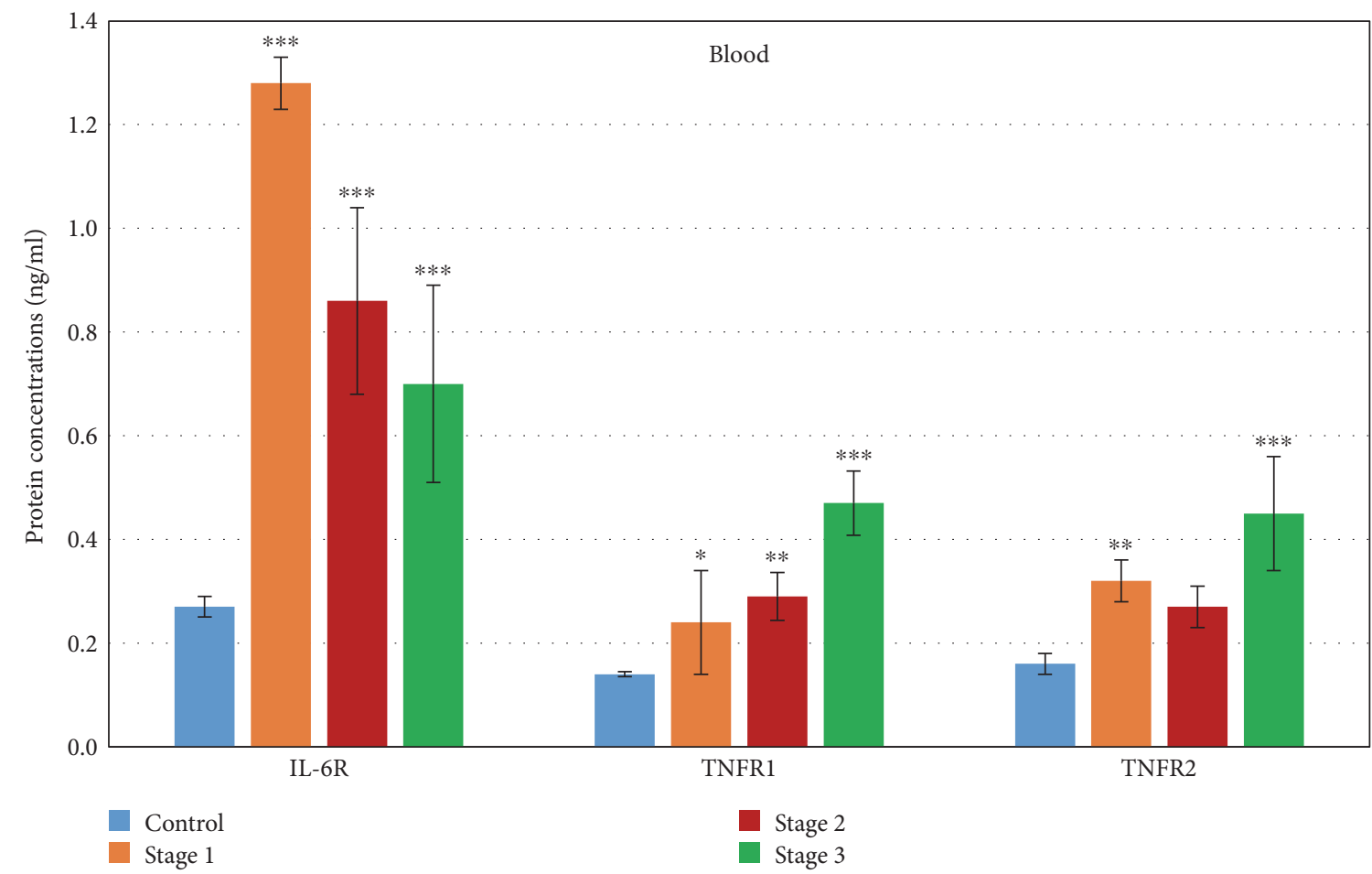

FIGURE 3: Expression of cytokine receptors on protein levels in blood of patients with different stages of TAA. The protein levels of all detected genes were compared to controls $(\mathrm{C}, n=10)$. All data are presented as average $\pm \mathrm{SD}$ : 1 -mean aortic diameter $43 \pm 2.3 \mathrm{~mm}(n=10), 2-$ mean aortic diameter $51 \pm 2.8 \mathrm{~mm}(n=34)$, 3-mean aortic diameter $59.5 \pm 3.7(n=14) .{ }^{*} p<0.05,{ }^{* *} p<0.01$, and ${ }^{* * *} p<0.001$ mean statistical significance.

According to the Spearman correlation coefficients (nonparametric correlation), a strong correlation exists between the rising expression of IL-6 mRNA and increased aorta diameter (Table 3). Linear regression showed using categorical variable aorta diameter as a dependent variable that if the aorta diameter increases about one then an expression of IL- 6 mRNA in tissue will be elevated about $0.710(p<0.001)$. Serum protein IL-6 did not correlate with the aorta diameter. The detection of mRNA levels of CRP in the aortic tissue (Figure 1) showed almost exponential growth from stage 1 to stage 3 against the control tissues.

Protein levels of CRP in blood serum (Figure 2) did not increase so dramatically. We found a maximal increase in stage 3 (about $151 \%$ times higher, $p<0.001$ ) in comparison with the control serum.
We also demonstrated that the mRNA of CRP is produced in aneurysmal tissue, and its rising concentrations are associated with aneurysmal size, proved by Spearman correlation (Table 3).

Serum protein CRP was not correlated with the aorta diameter, because its levels could be affected by multiple factors related to nonspecific inflammation or infection and not only by aortic tissue damage. The most significant differences in protein levels of the cytokine receptors in blood were detected using antibodies for IL-6 receptor, where we found decreasing levels of protein from stage 1 with $374 \%$ higher levels than the control $(p<0.001)$ to almost $159 \%$ higher against the control in stage $3(p<0.001)$ (Figure 3$)$.

In contrast to these data, the protein levels of both TNFR receptors (TNFR1 and 2) were significantly elevated to the 
TABLE 4: Spearman correlations and linear regression between the mRNA, protein levels, and aortic diameter for a selected member of ECM.

\begin{tabular}{|c|c|c|c|c|}
\hline & \multicolumn{3}{|c|}{ mRNA in aortic tissue } & \multirow{2}{*}{$\begin{array}{c}\text { Protein levels in blood } \\
\text { MMP9 }\end{array}$} \\
\hline & MMP9 & Emilin-1 & TIMP & \\
\hline Correlation coefficient & $0.386^{*}$ & $-0.496^{* *}$ & $0.470^{* *}$ & $0.320^{*}$ \\
\hline$p$ value & 0.048 & 0.015 & 0.025 & 0.045 \\
\hline Unstandardized coefficient & $0.193^{* * *}$ & $-0.533^{* * *}$ & $0.280^{* * *}$ & 0.007 \\
\hline$p$ value & 0.000 & 0.000 & 0.000 & 0.004 \\
\hline
\end{tabular}

${ }^{*} p<0.05,{ }^{* *} p<0.01$, and ${ }^{* * *} p<0.001$ mean statistical significance.

maximum in stage 3 (Figure 3), with values about $230 \%$ and $181 \%$ higher than controls (both with $p<0.001$ ).

During the statistical evaluation of Spearman correlation data, we found medium negative correlation between the aortic aneurysm diameter and protein levels of IL-6R $(\mathrm{rs}=-0.37, p<0.024)$. The protein levels of TNFR1 positively correlated nonsignificantly with the progress of TAA ( $\mathrm{rs}=0.272, p<0.058$ ). All data are shown in Table 3 .

3.2. Changes in the Expression of Components of ECM. The expression of Emilin-1 in aortic tissue on mRNA levels revealed a nonsignificant decrease from $28 \%$ less than control in stage 1 to a $70 \%$ smaller value against controls $(p<0.001)$ in stage 3. Linear regression showed using categorical variable aorta diameter as a dependent variable that if the aorta diameter increases about one then an expression of Emilin1 mRNA in tissue will be decreased about $0.533(p<0.001)$. The pathological changes in ECM were confirmed by the detection of mRNA for MMP9 and TIMP (Figure 1). We found that the increase in mRNA levels of MMP9 (with the maximum in stage 3 about $490 \%$ higher than controls, $p<0.001$ ) also affected the expression of TIMP; the mRNA levels of which were also elevated. Linear regression showed using categorical variable aorta diameter as a dependent variable that if the aorta diameter increases about one then an expression of MMP9 mRNA in tissue will be elevated about $0.193(p<0.001)$. Maximal levels of TIMP mRNA were detected in stage 3 , with the value about $340 \%$ higher than in controls $(p<0.001)$. Linear regression showed using categorical variable aorta diameter as a dependent variable that if the aorta diameter increases about one then an expression of TIMP mRNA in tissue will be elevated about $0.280(p<0.001)$. The MMP9 protein levels in the blood were measured in the time-course of the growing diameter of the thoracic aorta aneurysm. We found that protein levels of MMP9 were nonsignificantly elevated from the initial stage of TAA (52\% higher than controls) to highly significant levels about $372 \%$ higher in stage $3(p<0.001)$.

Spearman correlation of aneurysm diameter revealed a weak positive correlation in the mRNA of MMP9 ( $\mathrm{rs}=0.386, p<0.048$ ), which was also confirmed by the weak positive correlation of TAA progress with the blood level of protein MMP9 ( $r s=0.320, p<0.045)$. In agreement with this data, we found a medium positive correlation in mRNA levels of MMP9 and inhibitor TIMP ( $\mathrm{rs}=0.470, p<0.025$ ). The other marker of ECM degradation progress, Emilin-1, showed medium negative correlation with an aneurysm diameter on the mRNA level ( $r s=-0.496, p<0,015)$. All data are shown in Table 4.

3.3. Results of Spearman Correlation Analysis. The mRNA levels of both IL-6 and CRP had a similar rising ratio in the aortic tissue in all stages, which was also confirmed in the levels of both proteins in blood serum, where the IL- 6 concentrations were about $160 \%$ higher than the levels of CRP $(p<0.001)$. During the statistical analysis of obtained results, we found a highly significant positive correlation between the expressions of mRNA of IL- 6 in aortic tissue and protein levels of IL-6 in the blood ( $r s=0.449, p<0.01)$. A similar statistically significant positive correlation (Figure 4) was found between the mRNA expression of CRP in aortic tissue and protein levels of CRP in the blood ( $\mathrm{rs}=0.394, p<0.01$ ).

All of the results showed a strong positive correlation between mRNA levels of MMP9 and its protein MMP9 in blood ( $r s=0.989, p<0.001$ ), which suggests that the progressive pathological changes of the TAA tissue cause the release of MMP9 into the blood of patients. This fact is also supported by the strong positive correlation between mRNA levels of TIMP and MMP9 in the tissue ( $r s=0.934, p<0.01$, Figure 4). Linear regression revealed that if the level of MMP9 mRNA in tissue will be elevated about one then the mRNA of TIMP will be increased about $1.188(p<0.001)$. Because of the inhibitory activity of TIMP on MMP9, the imbalance between these genes is considered to be important in the degenerative process. Linear regression showed using categorical variable MMP9 mRNA as a dependent variable and protein MMP9 as an independent variable that if concentration of mRNA in tissue increases about one then the level of protein MMP9 in blood will be elevated about $0.013(p<0.051)$. Similarly to that also linear regression showed using IL- 6 mRNA as a dependent variable and protein IL- 6 as an independent variable that if concentration of mRNA in tissue increases about one then the level of protein IL-6 in blood will be elevated about $0.021(p<0.022)$.

\section{Discussion}

The occurrence and expansion of an aneurysm probably depend on local hemodynamic factors and intrinsic factors of the affected arterial segment. The medial layer of the aorta wall is responsible for its tensile elasticity and strength. During the formation of thoracic aorta aneurysm, elastin content in the ECM of the ascending aorta is progressively degrading. The activity and gene expression of specific enzymes (TGF, MMP) are increased, and this leads to the 

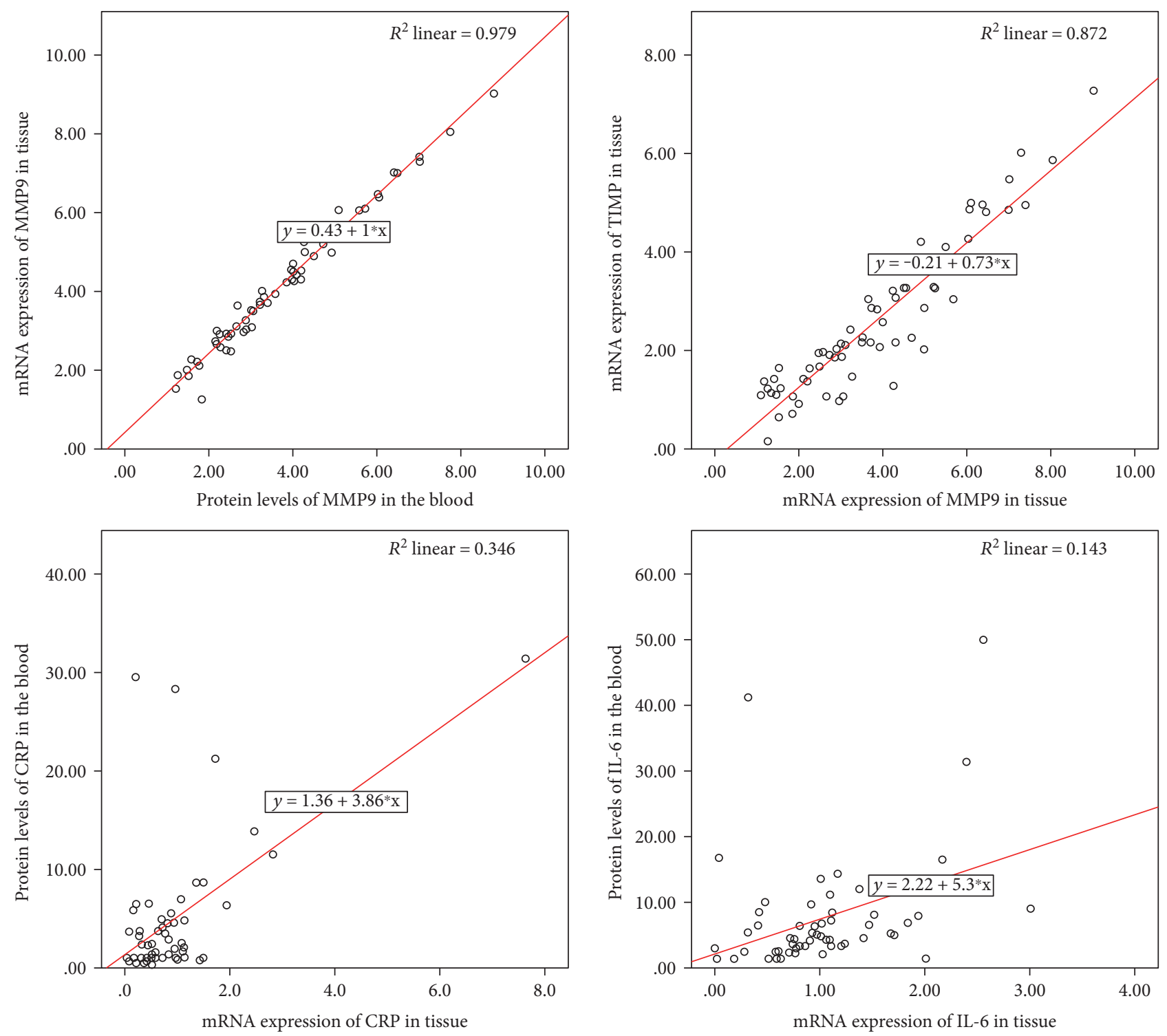

FIgURE 4: Graphical expression of the Spearman correlation of selected cytokines and markers of ECM damage.

degradation of the structural proteins (elastin, fibullin, and collagen). Elastic fibre fragmentation and loss together with degeneration of the media result in a weakening of the aortic wall, loss of elasticity, and consequent dilation [19].

One of the main members of ECM is Emilin-1 [20]. Emilin-1 has multiple roles, like inhibiting elastin deposition by smooth muscle cells (SMC) [21] as well as regulation of the bioavailability of TGF- $\beta$ by inhibiting proteolysis of the proTGF- $\beta$ precursor to LAP/TGF- $\beta$, a complex from which the growth factor can be subsequently released for receptor binding [22]. The absence of Emilin-1 causes a remarkable increase of active TGF- $\beta$, which consequently through the SMAD cascade upregulates genes involved in ECM destruction (MMP9) or decreases SMC proliferation (p27) [23]. The importance of Emilin-1 expression was also confirmed by the experiment of Pivetta et al. [10], which showed that mice deficient in Emilin-1 had increased TGF- $\beta$ activity; however, these mice had a low incidence of aneurysms and no dissection. Another study, by Lee et al. [24], however, showed that embryonic mutation of the type II TGF- $\beta$ receptor gene $(T g f b r 2)$ impaired elastogenesis and resulted in aneurysm formation and inflammation. We found that the increasing diameter of aortic aneurysm significantly correlates negatively with decreasing levels of Emilin-1 mRNA in the affected tissue, which confirmed the direct involvement of Emilin-1 in the regulation of degradation processes of ECM in the aortic wall.

Another impairment in the maintaining of physiological conditions of ECM in aortic wall is upregulation of the expression of MMPs, which are defined as proteases produced by leukocytes and smooth muscle cells (SMCs) within the aortic wall and acting on a variety of extracellular protein substrates [25]. Specific MMP9 degrades type IV collagen, elastin, and various basement membrane proteins of SMCs. Its expression increases within 3 hours of the onset of dissection [11]. Ruddy et al. [26] observed that the activity 
of protein MMP9 in the aortic tissue of patients with Marfan syndrome, detected by zymography, was increased in comparison to controls. They also found that the concentration of protein MMP9 in the blood was significantly elevated as compared to controls. Gene expression analyses in animal models made by Trollope et al. [27] demonstrated the upregulation of the mRNA encoding MMP9 corresponding to increased extracellular matrix degradation. The results of Swedenborg et al. [28] have determined that the main producers of MMP9 in normal human aorta are mast cells. They found a higher amount of MMP9 in comparison to their expression in atherosclerosis, which demonstrates their involvement in extracellular matrix degradation, smooth muscle cell apoptosis, renin-angiotensin system activity, and neovascularization. In agreement with those results, we detected significantly elevated levels of both mRNA in aortic tissue (about $490 \%$ higher than controls in stage 3 ) and protein levels (with a maximum in the same stage of about $340 \%$ higher than controls). According to the statistically strong correlation between mRNA, protein levels of MMP9, and aortic diameter, we suggest that MMP9 expression was shown to be directly dependent on aneurysm diameter. For more precise confirmation, we measured the expression of mRNA for TIMP.

TIMP1 inhibits the activities of all MMPs and plays a role in regulating ECM in different physiological processes [26]. Structure function studies have separated the MMP inhibitory activity of TIMP1 from its growth promoting effect [29]. These TIMPs can express MMP-dependent and MMP-independent actions in the regulation of cell death, cell proliferation, and angiogenesis, involving specific signal transduction pathways. Several studies exist describing the ratio of MMP9 to TIMP1 expression in TAA. The study of Mi et al. [30] revealed that the ratio of MMP9 to TIMP1 in TAA tissue was 3.7-fold higher in TAA compared to controls. Another study of Ikonomidis et al. [31] confirmed the ratio of MMP9/TIMP1 was over 3.5-fold greater than controls. We found elevated mRNA levels of TIMP1 in all stages of TAA (with a maximum in stage 3, with levels about $340 \%$ higher than controls). We also correlated the mRNA ratio of MMP9 and TIMP and confirmed 1.7-fold higher values in aortic tissue against controls. Therefore, we suggest that an imbalance between MMP and TIMP expression is responsible for the shift toward a proteolytic state of ECM.

SMC apoptosis and ECM destruction in the aortic wall are accompanied by an increased degree of inflammation [11]. Several cytokines and chemokines that promote the recruitment of inflammatory cells to the aortic wall, such as tumour necrosis factor $\alpha$, interferon (IFN)- $\gamma$, and interleukins IL-2 and IL-6 are upregulated [12]. These findings indicate that damage to the ECM, resulting in elastic fibre fragmentation, can trigger an inflammatory process by recruiting, activating, and inducing the differentiation of immune cells.

A classical plasma protein marker of acute phase of inflammation, infection, and tissue damage is CRP [32]. CRP is mainly expressed by hepatocytes, and its synthesis is regulated at the posttranscriptional level by cytokines, mainly by IL-6 with a synergic effect of IL-1 [13]. CRP can also be produced locally in atherosclerotic lesions [33]. A study by
De Haro et al. [34] showed that patients with symptomatic and ruptured aneurysms had elevated serum CRP compared with patients with asymptomatic AAA. CRP directly influences several phases of atherosclerosis via complement activation, apoptosis, vascular cell activation, monocyte recruitment, lipid accumulation, and thrombosis [35]. CRP was normal and increased significantly since day 2 in the impaired oxygenation group [36]. Increased admission CRP correlated with high mortality irrespective of management policy [37]. However, Sakakura et al. [38] proposed that it may take 3-6 days to reach peak CRP; thus, initial CRP levels might not reflect the whole severity of aortic dissection. Our findings showed a rising concentration of both CRP mRNA in the tissue and also protein CRP in the blood of patients with a growing size of aortic diameter. Therefore, we supported the increasing inflammation in the TAA tissue and its spreading into the bloodstream, which was confirmed by elevated levels of IL- 6 protein and mRNA in the blood and tissue.

IL-6 is involved in acute and chronic inflammation associated with aneurysm formation [39]. Both thoracic and abdominal aortic aneurysms are positively correlated to high circulating levels of IL-6 [13]. We found that soluble IL-6 in the samples with the highest aortic diameter had levels elevated by about $84 \%$ in comparison to controls. Our results are also confirmed by the study of Dawson et al. [40]. They demonstrated that TAA is a source of IL-6 in circulation, which was also demonstrated in the study of Golledge et al. [41], which showed that IL-6 values in AAA patients increased in a stepwise fashion among groups of aortic size and peaked in patients with aortic dilatation. This result confirmed that the aneurysm tissue is the source of the soluble IL-6, which is probably one of the key factors required for promoting Th17 cell differentiation; thus, one of the possible mechanisms of IL- 6 action could be the regulation of Th17 cells in progression of TAA.

Another marker of increased inflammation enhanced by aortic dilatation is IL- 6 receptor, which forms a dimer with the ubiquitously expressed signal transducer glycoprotein130 (gp-130). Attachment of IL-6 to its receptor leads to the activation of the intracellular receptor-associated kinases and downstream effects via the transcription factor STAT3. The membrane-bound IL-6R (mIL-6R) is expressed in hepatocytes and cells of the innate immune system. In transsignalling, IL-6 binds to the circulating soluble IL-6R (sIL-6R), and this complex is capable of binding to gp130 in a wide range of cell types [42]. It has previously been shown that the expression of IL- 6 and downstream mediators of IL- 6 signalling, such as STAT3, are greater in AAA than in nonaneurysmal aortic tissue [32]. Till now, no data exists comparing the soluble protein of IL-6R concentrations and the diameter of TAA. We found a medium negative correlation of IL-6R with the diameter of aorta aneurysm.

We also studied the effect of the inflammatory cytokine TNF- $\alpha$ according to the expression of its receptors in the blood. TNF- $\alpha$ initiates its biological actions by binding to a $55-\mathrm{KDa}$ receptor (TNFR1) or a 75-KDa receptor (TNFR2) [43]. TNFR1 is constitutively expressed in most tissues, binding primarily to the soluble form of TNF- $\alpha$, and is the key mediator of TNF- $\alpha$ signalling in many cell types. TNFR2 is 
typically expressed in endothelial- and immune-related cells and is activated by membrane-bound TNF- $\alpha$. The major difference between the two receptors is the death domain (DD) of TNFR1 that is absent in TNFR2. Meng et al. [44] suggest that during early stages of aneurysm formation, TNFR2 signalling is activated by membrane-bound TNF- $\alpha$ and when sufficient TNF- $\alpha$ is secreted, it activates TNFR1 signalling, resulting in inflammation and apoptosis [45]. We found that both TNFR receptors (TNFR1 and TNFR2) had protein levels significantly elevated to the maximum in the group of patients with the higher aneurysm diameter. This confirms the nonsignificantly positive correlation of TNFR receptors with the progress of TAA.

\section{Conclusion}

The asymptomatic progress of TAA predetermines the detection of early pathological changes in aortic tissue as one of the most important goals of current cardiovascular treatment. Recently used detection techniques (ultrasonography and MRI) have very high specificity and efficiency. However, the possibility of repeating measurements during the control examination is limited regardless of the time occupancy of individual scanning equipment. Therefore, the aims of this paper were focused on the detection of basic inflammatory markers as well as markers of ECM degradation in both the aortic wall and blood. From the obtained results, a positive correlation of parameters like IL-6, CRP, TNFR1, and TNFR2 together with MMP9 and TIMP between the growing diameter of aneurysm and mRNA from tissue or protein levels from blood is obvious, although we also found significant negative correlation of Emilin-1 mRNA in the tissue and protein soluble receptor of IL-6 in the blood, which suggests that the release of inflammatory mediators dramatically increases the degradation of ECM in the aortic wall. Changes of gene expression of selected genes can be used for more purposes, like the detection of progressive pathological changes of aortic wall, for the experimental study of the inflammatory receptor inhibitors or effect of the gene polymorphism on the receptor functions during trials targeted on slowing down the progress of aortic wall aneurysm or for a decision about the consequential surgical options of wall recovery.

\section{Conflicts of Interest}

The authors state that there are no conflicts of interest regarding the publication of this article.

\section{Acknowledgments}

The authors would like to thank Peter Kolarčík from the Department of Health Psychology, Faculty of Medicine, UPJŠ, for the statistical support. This work was supported by the projects VEGA 1/0873/16 and VEGA 1/0115/14.

\section{References}

[1] M. Bashir, M. Fok, I. Hammoud et al., "A perspective on natural history and survival in nonoperated thoracic aortic aneurysm patients," Aorta, vol. 1, pp. 182-189, 2013.
[2] C. A. Nienaber, H. Ince, F. Weber et al., "Emergency stentgraft placement in thoracic aortic dissection and evolving rupture," Journal of Cardiac Surgery, vol. 18, pp. 464-470, 2003.

[3] I. Vulev, A. Klepanec, T. Balazs, and M. Holoman, "Endovascular treatment of late in-stent-graft dissection after thoracic endovascular aneurysm repair," Cardiovascular and Interventional Radiology, vol. 34, pp. 864-867, 2011.

[4] G. Albornoz, M. A. Coady, M. Roberts et al., "Familial thoracic aortic aneurysms and dissections-incidence, modes of inheritance, and phenotypic patterns," The Annals of Thoracic Surgery, vol. 82, pp. 1400-1405, 2006.

[5] R. R. Gopaldas, J. Huh, T. K. Dao et al., "Superior nationwide outcomes of endovascular versus open repair for isolated descending thoracic aortic aneurysm in 11,669 patients," The Journal of Thoracic and Cardiovascular Surgery, vol. 140, pp. 1001-1010, 2010.

[6] J. M. Ruddy, J. A. Jones, and J. S. Ikonomidis, "Pathophysiology of thoracic aortic aneurysm (TAA): is it not one uniform aorta? Role of embryologic origin," Progress in Cardiovascular Diseases, vol. 56, pp. 68-73, 2013.

[7] H. H. Chiu, M. H. Wu, H. C. Chen, F. Y. Kao, and S. K. Huang, "Epidemiological profile of Marfan syndrome in a general population: a national database study," Mayo Clinic Proceedings, vol. 89, pp. 34-42, 2014.

[8] C. M. Kielty, C. Baldock, D. Lee, M. J. Rock, J. L. Ashworth, and C. A. Shuttleworth, "Fibrillin: from microfibril assembly to biomechanical function," Philosophical Transactions of the Royal Society B: Biological Sciences, vol. 357, pp. 207-217, 2002.

[9] L. Zilberberg, V. Todorovic, B. Dabovic et al., "Specificity of latent TGF- $\beta$ binding protein (LTBP) incorporation into matrix: role of fibrillins and fibronectin," Journal of Cellular Physiology, vol. 227, pp. 3828-3836, 2012.

[10] E. Pivetta, B. Wassermann, B. L. Del Bel et al., "Local inhibition of elastase reduces EMILIN1 cleavage reactivating lymphatic vessel function in a mouse lymphoedema model," Clinical Science, vol. 130, pp. 1221-1236, 2016.

[11] D. Wu, J. C. Choi, A. Sameri et al., "Inflammatory cell infiltrates in acute and chronic thoracic aortic dissection," Aorta, vol. 1, pp. 259-267, 2013.

[12] F. del Porto, M. Proietta, L. Tritapepe et al., "Inflammation and immune response in acute aortic dissection," Annals of Medicine, vol. 42, pp. 622-629, 2010.

[13] P. Artemiou, N. Charokopos, E. Rouska et al., "C-reactive protein/interleukin-6 ratio as marker of the size of the uncomplicated thoracic aortic aneurysms," Interactive Cardiovascular and Thoracic Surgery, vol. 15, pp. 871-877, 2012.

[14] E. Allaire, F. Schneider, F. Saucy et al., "New insight in aetiopathogenesis of aortic diseases," European Journal of Vascular \& Endovascular Surgery, vol. 37, pp. 531-537, 2009.

[15] V. Arpino, M. Brock, and S. E. Gill, "The role of TIMPs in regulation of extracellular matrix proteolysis," Matrix Biology, vol. 44-46, pp. 247-254, 2015.

[16] L. Geng, W. Wang, Y. Chen et al., "Elevation of ADAM10, ADAM17, MMP-2 and MMP-9 expression with media degeneration features $\mathrm{CaCl}^{2}$-induced thoracic aortic aneurysm in a rat model," Experimental and Molecular Pathology, vol. 89, pp. 72-81, 2010.

[17] C. S. Moore and S. J. Crocker, "An alternate perspective on the roles of TIMPs and MMPs in pathology," The American Journal of Pathology, vol. 180, pp. 12-16, 2012. 
[18] H. H. Yang, J. M. Kim, E. Chum, C. van Breemen, and A. W. Chung, "Effectiveness of combination of losartan potassium and doxycycline versus single-drug treatments in the secondary prevention of thoracic aortic aneurysm in Marfan syndrome," The Journal of Thoracic and Cardiovascular Surgery, vol. 140, pp. 305-12, e2, 2010.

[19] N. Torma, V. Sihotsky, I. Kopolovets et al., "Surgical prevention of acute stroke in atherosclerotic carotid stenosis," Klinichna Khirurhiia, pp. 26-28, 2015.

[20] G. Litteri, D. Carnevale, A. D'Urso et al., "Vascular smooth muscle Emilin-1 is a regulator of arteriolar myogenic response and blood pressure," Arteriosclerosis, Thrombosis, and Vascular Biology, vol. 32, pp. 2178-2184, 2012.

[21] M. Rabajdova, P. Urban, I. Spakova et al., "The crucial role of emilin 1 gene expression during progression of tumor growth," Journal of Cancer Research and Clinical Oncology, vol. 142, no. 11, pp. 2397-2402, 2016.

[22] M. Shimodaira, T. Nakayama, N. Sato et al., "Association study of the elastin microfibril interfacer 1 (EMILIN1) gene in essential hypertension," American Journal of Hypertension, vol. 23, pp. 547-555, 2010.

[23] C. Shen, X. Lu, Y. Li et al., "Emilin1 gene and essential hypertension: a two-stage association study in northern Han Chinese population," BMC Medical Genetics, vol. 10, p. 118, 2009.

[24] V. S. Lee, C. M. Halabi, E. P. Hoffman et al., "Loss of function mutation in LOX causes thoracic aortic aneurysm and dissection in humans," Proceedings of the National Academy of Sciences of the United States of America, vol. 113, pp. 8759-8764, 2016.

[25] Y. Qin, X. Cao, Y. Yang, and G. P. Shi, "Cysteine protease cathepsins and matrix metalloproteinases in the development of abdominal aortic aneurysms," Future Cardiology, vol. 9, pp. 89-103, 2013.

[26] J. M. Ruddy, J. A. Jones, R. E. Stroud, R. Mukherjee, F. G. Spinale, and J. S. Ikonomidis, "Differential effect of wall tension on matrix metalloproteinase promoter activation in the thoracic aorta," The Journal of Surgical Research, vol. 160, pp. 333-339, 2010.

[27] A. Trollope, J. V. Moxon, C. S. Moran, and J. Golledge, "Animal models of abdominal aortic aneurysm and their role in furthering management of human disease," Cardiovascular Pathology, vol. 20, pp. 114-123, 2011.

[28] J. Swedenborg, M. I. Mayranpaa, and P. T. Kovanen, "Mast cells: important players in the orchestrated pathogenesis of abdominal aortic aneurysms," Arteriosclerosis, Thrombosis, and Vascular Biology, vol. 31, pp. 734-740, 2011.

[29] S. A. Mohamed, F. Noack, K. Schoellermann et al., "Elevation of matrix metalloproteinases in different areas of ascending aortic aneurysms in patients with bicuspid and tricuspid aortic valves," The Scientific World Journal, vol. 2012, article 806261, 7 pages, 2012.

[30] T. Mi, B. Nie, C. Zhang, and H. Zhou, "The elevated expression of osteopontin and NF- $\kappa \mathrm{B}$ in human aortic aneurysms and its implication," Journal of Huazhong University of Science and Technology [Medical Sciences], vol. 31, pp. 602-607, 2011.

[31] J. S. Ikonomidis, J. M. Ruddy, S. M. Benton Jr. et al., “Aortic dilatation with bicuspid aortic valves: cusp fusion correlates to matrix metalloproteinases and inhibitors," The Annals of Thoracic Surgery, vol. 93, pp. 457-463, 2012.
[32] M. Liao, C. L. Liu, B. J. Lv et al., "Plasma cytokine levels and risks of abdominal aortic aneurysms: a population-based prospective cohort study," Annals of Medicine, vol. 47, pp. 245-252, 2015.

[33] E. Garrafa, A. Giacomelli, M. Ravanelli et al., "Prediction of abdominal aortic aneurysm calcification by means of variation of high-sensitivity C-reactive protein," JRSM Cardiovascular Disease, vol. 5, article 2048004016682177, 2016.

[34] J. De Haro, S. Bleda, and F. Acin, "C-reactive protein predicts aortic aneurysmal disease progression after endovascular repair," International Journal of Cardiology, vol. 202, pp. 701-706, 2016.

[35] L. Speelman, F. A. Hellenthal, B. Pulinx et al., "The influence of wall stress on AAA growth and biomarkers," European Journal of Vascular \& Endovascular Surgery, vol. 39, pp. 410-416, 2010.

[36] S. K. Venugopal, S. Devaraj, and I. Jialal, "Macrophage conditioned medium induces the expression of C-reactive protein in human aortic endothelial cells: potential for paracrine/autocrine effects," The American Journal of Pathology, vol. 166, pp. 1265-1271, 2005.

[37] T. Suzuki, A. Distante, and K. Eagle, "Biomarker-assisted diagnosis of acute aortic dissection: how far we have come and what to expect," Current Opinion in Cardiology, vol. 25, pp. 541-545, 2010.

[38] K. Sakakura, N. Kubo, J. Ako et al., "Peak C-reactive protein level predicts long-term outcomes in type B acute aortic dissection," Hypertension, vol. 55, pp. 422-429, 2010.

[39] I. Hinterseher, G. Tromp, and H. Kuivaniemi, "Genes and abdominal aortic aneurysm," Annals of Vascular Surgery, vol. 25, pp. 388-412, 2011.

[40] J. Dawson, G. W. Cockerill, E. Choke, A. M. Belli, I. Loftus, and M. M. Thompson, "Aortic aneurysms secrete interleukin-6 into the circulation," Journal of Vascular Surgery, vol. 45, pp. 350-356, 2007.

[41] J. Golledge, P. S. Tsao, R. L. Dalman, and P. E. Norman, "Circulating markers of abdominal aortic aneurysm presence and progression," Circulation, vol. 118, pp. 23822392, 2008.

[42] J. Wolf, G. H. Waetzig, A. Chalaris et al., "Different soluble forms of the interleukin- 6 family signal transducer gp130 fine-tune the blockade of interleukin-6 trans-signaling," The Journal of Biological Chemistry, vol. 291, pp. 1618616196, 2016.

[43] S. Lindberg, M. Zarrouk, J. Holst, and A. Gottsater, "Inflammatory markers associated with abdominal aortic aneurysm," European Cytokine Network, vol. 27, pp. 75-80, 2016.

[44] X. Meng, J. Yang, K. Zhang et al., "Regulatory T cells prevent angiotensin II-induced abdominal aortic aneurysm in apolipoprotein E knockout mice," Hypertension, vol. 64, pp. 875-882, 2014.

[45] C. Duerrschmid, J. Trial, Y. Wang, M. L. Entman, and S. B. Haudek, "Tumor necrosis factor: a mechanistic link between angiotensin-II-induced cardiac inflammation and fibrosis," Circulation: Heart Failure, vol. 8, pp. 352-361, 2015. 


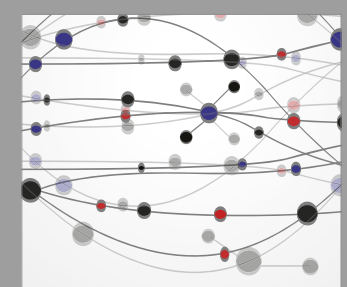

The Scientific World Journal
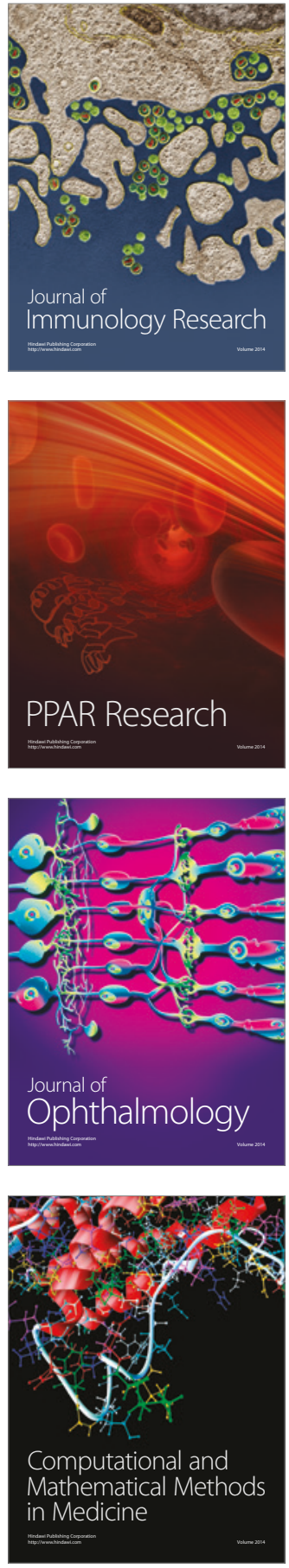

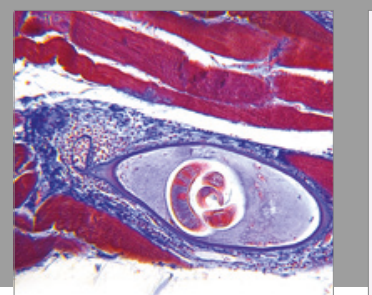

Gastroenterology Research and Practice
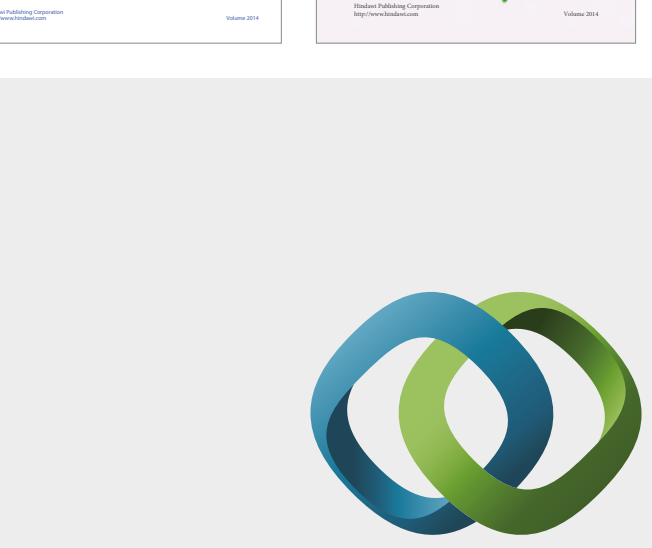

\section{Hindawi}

Submit your manuscripts at

https://www.hindawi.com
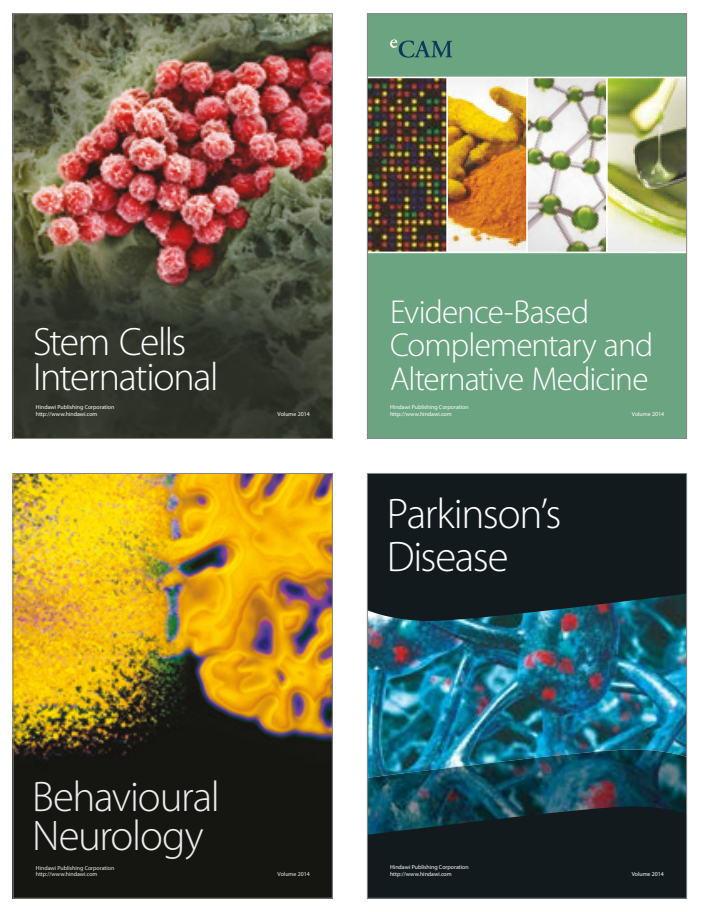
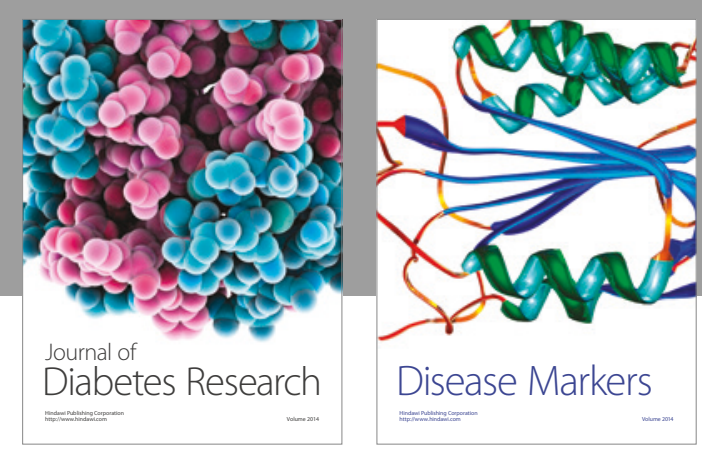

Disease Markers
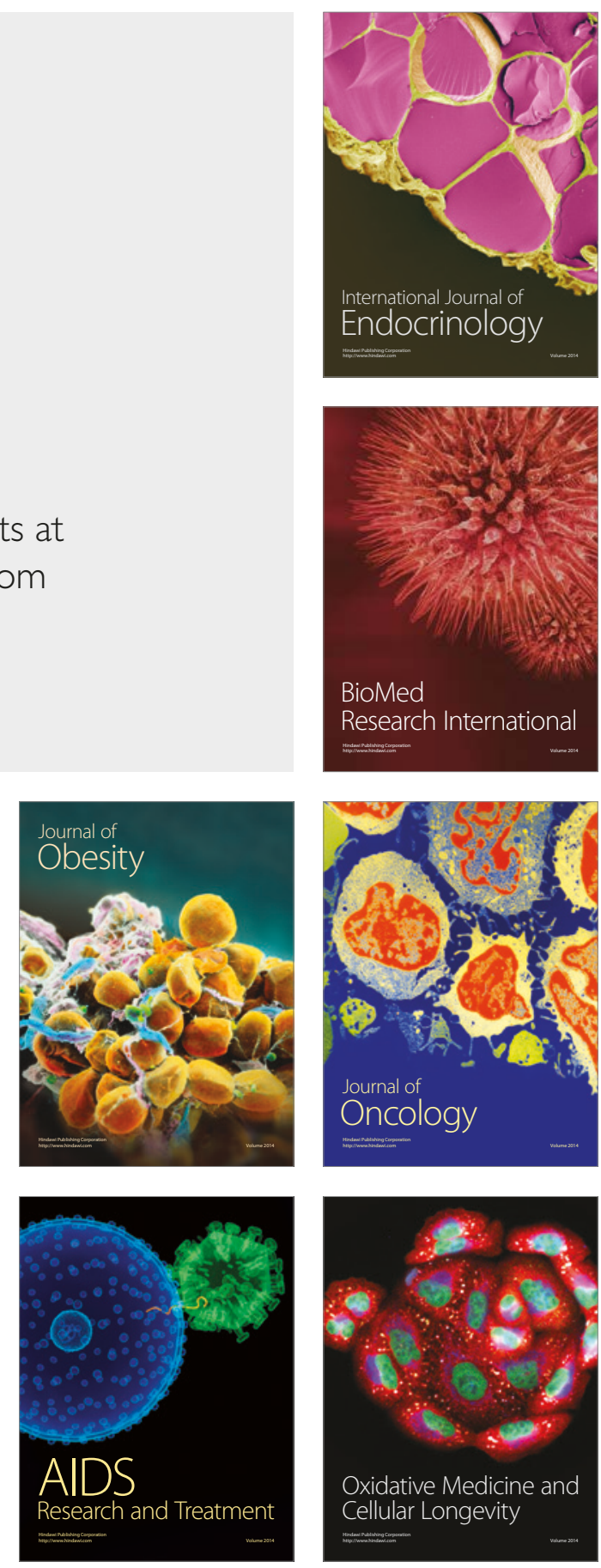